06

\title{
Аномалии упругих и неупругих свойств наногранулированных композиционных материалов $\mathrm{Co}_{x}\left(\mathrm{CaF}_{2}\right)_{100-x}$
}

\author{
() Д.П. Тарасов
}

Военный учебно-научный центр Военно-воздушных сил Военно-воздушная академия им. проф. Н.Е.Жуковского и Ю.А. Гагарина,

394064 Воронеж, Россия

e-mail: demetriys@mail.ru

Поступило в Редакцию 21 июня 2018г.

В окончательной редакции 1 декабря 2018г.

Принято к публикации 1 декабря 2018 г.

В интервале температур 170-750 К изучены упругие $(G)$ и неупругие $\left(Q^{-1}\right)$ свойства нанокомпозитов $\mathrm{Co}_{x}\left(\mathrm{CaF}_{2}\right)_{100-x}(x=41-84$ at.\%), полученных методом ионно-лучевого распыления. При температуре $227 \mathrm{~K}$ обнаружены максимумы внутреннего трения, связанные с прыжковым движением атомов Со внутри металлических гранул. Установлено, что величина максимумов растет с увеличением концентрации металлической фазы. Выше 675 К отмечен существенный рост зависимости $Q^{-1}(T)$, вызванный диффузионным движением вакансий в гранулах Со в условиях ограниченной геометрии.

DOI: $10.21883 /$ JTF.2019.06.47638.245-18

\section{Введение}

Гранулированные композиты системы ферромагнетик-диэлектрик демонстрируют ряд физических свойств, отличающих их от обычных материалов $[1,2]$. Использование в композите в качестве диэлектрика сегнетоэлектрического материала позволяет ожидать появления новых свойств, например, возникновения магнитоэлектрического эффекта. Данный эффект может иметь место благодаря стрикционной связи, реализующейся между частицами ферромагнетика и сегнетоэлектрика в результате их упругого взаимодействия.

В связи с этим целью настоящей работы стало получение и исследование упругих и неупругих свойств нанокомпозитов $\mathrm{Co}_{x}\left(\mathrm{CaF}_{2}\right)_{100-x}$.

\section{Методика}

Нанокомпозиционные материалы системы $\mathrm{Co}_{x}\left(\mathrm{CaF}_{2}\right)_{100-x}$ были получены методом ионно-лучевого распыления составной мишени на подложку из ситалла. Мишень представляла собой пластину из кобальта размером $280 \times 80 \times 10 \mathrm{~mm}$, на поверхности которой были укреплены навески керамики $\mathrm{CaF}_{2}$ размером $80 \times 10 \times 2 \mathrm{~mm}$. Применение мишени такой конструкции позволило в одном технологическом цикле получить композиционный материал в виде пленки и толщиной около $2 \mu \mathrm{m}$, содержащей от 41 до $84 \mathrm{at} . \%$ металлической фазы в зависимости от взаимного расположения подложки и мишени. Структура пленки исследовалась с помощью растрового электронного микроскопа JSM-6380, a еe состав определялся c помощью электронно-зондового рентгеновского микроанализатора. Микрофотография поверхности образца представлена на рис. 1. Видно, что полученная структура является гранулированной с размерами гранул $d \approx 1.5-4.5 \mathrm{~nm}$ в зависимости от концентрации $x$.

Образцы для измерения внутреннего трения $\left(Q^{-1}\right)$ и упругого модуля $(G)$ представляли пластины из кремния или ситалла с напыленным на одну из поверхностей композиционным материалом толщиной около $2 \mu \mathrm{m}$. Образцы имели прямоугольную форму размером $5 \times 18 \times 0.4 \mathrm{~mm}$. Измерения температурных зависимостей $G$ и $Q^{-1}$ проводили методом затухания изгибных колебаний на частоте около $20 \mathrm{~Hz}$ в интервале температур от 170 до $750 \mathrm{~K}$ при скорости нагрева $3 \mathrm{~K} / \mathrm{min}$ в вакууме. Погрешность определения $Q^{-1}$ и $G$ не превышала 3 и $1 \%$ соответственно.

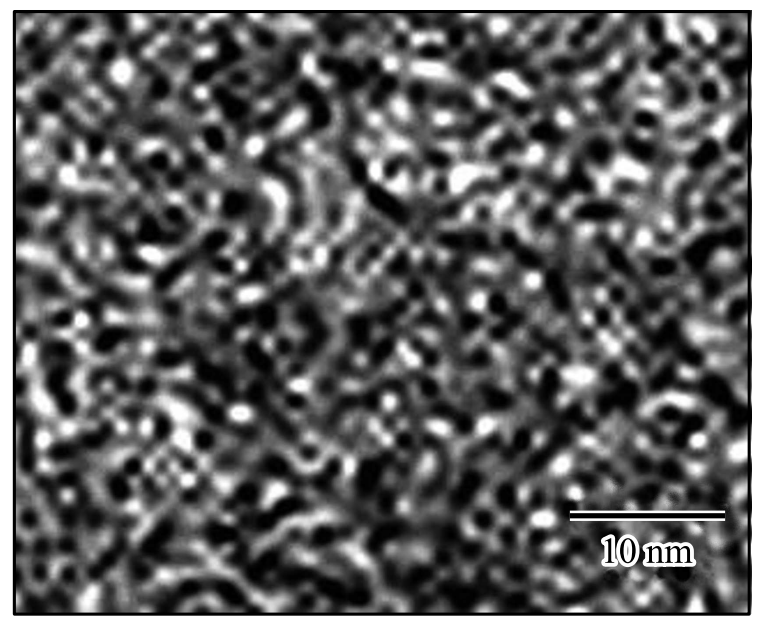

Рис. 1. Микрофотография поверхности свежеприготовленного образца $\mathrm{Co}_{75}\left(\mathrm{CaF}_{2}\right)_{25}$. 
Внутреннее трение рассчитывалось по формуле [3]:

$$
Q^{-1}=\frac{1}{\pi \mathrm{N}} \ln \frac{\mathrm{A}_{1}}{\mathrm{~A}_{\mathrm{N}}}
$$

где $N$ - число колебаний образца при изменении амплитуды от $A_{1}$ до $A_{N}$.

Внутреннее трение композита определялось путем вычитания из внутреннего трения исследуемого образца внутреннего трения подложки.

Для измерения частоты колебаний использовался частотомер, показания которого служили для определения относительного модуля упругости

$$
G=\frac{f^{2}}{f_{0}^{2}}
$$

где $f^{2}$ и $f_{0}^{2}$ - квадрат частоты колебаний образца при текущей и начальной температуре $T_{0}$ соответственно.

\section{Результаты и их обсуждение}

Рассмотрим результаты исследования упругих и неупругих свойств, полученные для свежеприготовленных образцов наногранулированных композиционных материалов $\mathrm{Co}_{x}\left(\mathrm{CaF}_{2}\right)_{100-x}$ в области температур $170-750 \mathrm{~K}$.

На кривых $Q^{-1}(T)$, полученных для свежеприготовленных образцов, в окрестностях $227 \mathrm{~K}$ обнаружен максимум внутреннего трения. Его высота зависит от объема металлической фракциии возрастает с увеличением последней (рис. 2). Экспериментально полученным пикам $Q^{-1}$ соответствует смягчение упругого модуля $G$ (рис. 3 ).

Тот факт, что высота пика $Q^{-1}$ растет с увеличением концентрации металлической фазы, свидетельствует о затухании механических колебаний в аморфной структуре металлического сплава $\mathrm{Co}_{x}\left(\mathrm{CaF}_{2}\right)_{100-x}$. Исследования внутреннего трения в сплавах с аморфной структурой показали наличие максимумов в диапазоне низких температур. Природа этого пика связывается с термоактивированной перестройкой атомной структуры аморфной металлической фазы под действием механических напряжений [4].

Можно предположить, что наблюдаемые в материалах $\mathrm{Co}_{x}\left(\mathrm{CaF}_{2}\right)_{100-x}$ аномалии $Q^{-1}$ имеют одинаковую природу и связаны с перескоками атомов Со в металлических зернах под действием механических напряжений [4]. В этом случае энергию активации релаксационного процесса можно оценить по формуле Верта

$$
E=k T_{m} \ln \frac{k T_{m}}{h f} .
$$

Здесь $T_{m}-$ температура максимума внутреннего трения, $h-$ постоянная Планка, $k-$ постоянная Больцмана.

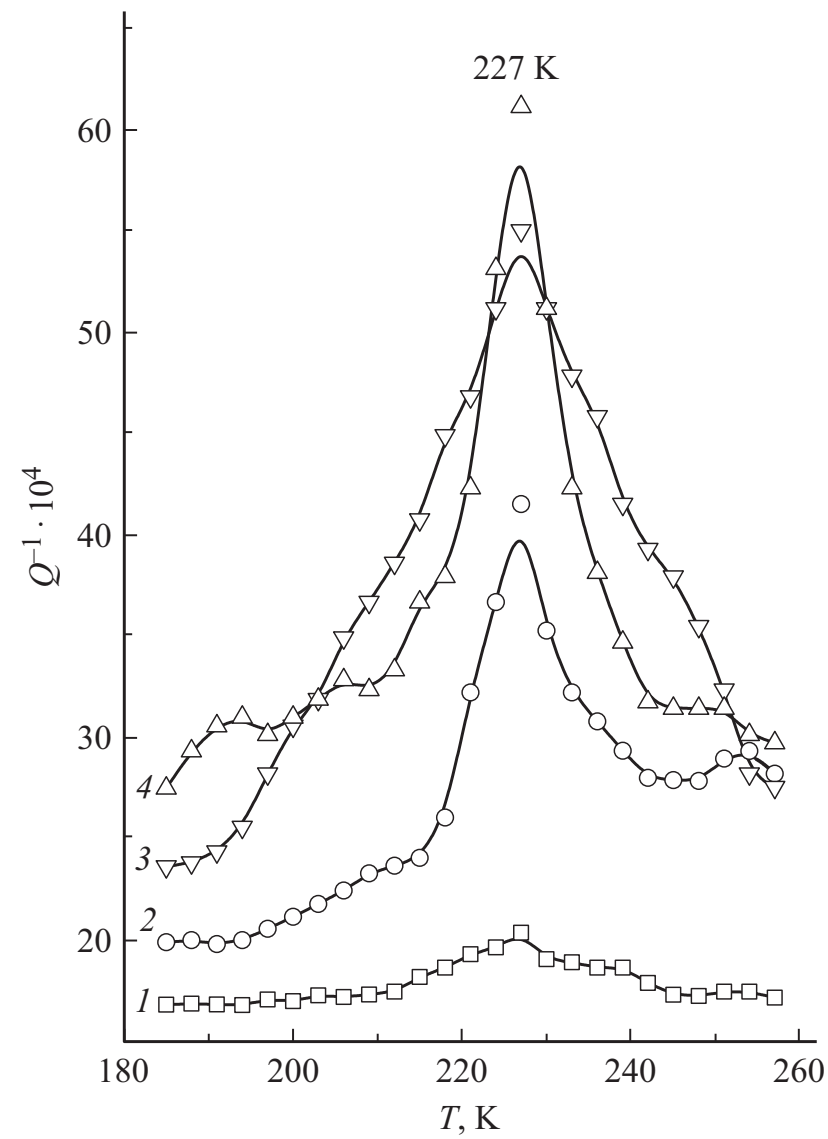

Рис. 2. Температурные зависимости $Q^{-1}$ нанокомпозитов $\mathrm{Co}_{x}\left(\mathrm{CaF}_{2}\right)_{100-x}$ при различной концентарции металлической фазы $x$, at.\%: $1-80 ; 2-75 ; 3-70 ; 4-57$.

Подставив в (3) экспериментальные значения $T_{m}$ и $f$, найдем энергию активации пиков, наблюдаемых для нанокомпозитов $\mathrm{Co}_{x}\left(\mathrm{CaF}_{2}\right)_{100-x}$ при температуре $227 \mathrm{~K}$. Определенная таким образом по формуле Верта энергия активации составила $0.5 \pm 0.1 \mathrm{eV}$. Данное значение совпадает с соответствующей величиной $E$ для композита $\left(\mathrm{Co}_{0.45} \mathrm{Fe}_{0.45} \mathrm{Zr}_{0.1}\right)_{x}\left(\mathrm{Al}_{2} \mathrm{O}_{3}\right)_{1-x}$ и $\mathrm{Co}_{x}(\mathrm{PZT})_{100-x}$, для которых ранее обнаружен аналогичный максимум $Q^{-1}$ [5].

Величины энергии активации, определенной по формуле Верта, хорошо согласуются с оценками энергии активации упругой релаксации, сделанными по методу полуширины максимума $Q^{-1}$ для соответствующих материалов [6-8].

В области температур, лежащей выше обсуждаемого максимума внутреннего трения, обнаружено монотонное уменьшение модуля $\mathrm{G}$, сопровождающееся ростом механических потерь с повышением температуры (рис. 4). Причем вне зависимости от концентрации металлической фазы величина $Q^{-1}$ слабо изменяется вплоть до температуры $650 \mathrm{~K}$ (кривые $1-4$ на рис. 4, $a$ ). При дальнейшем увеличении температуры происходит рост $Q^{-1}$, сопровождающийся существенным смягчением упругого модуля $G$ (кривая $l^{\prime}-4^{\prime}$ на рис. $4, b$ ). 


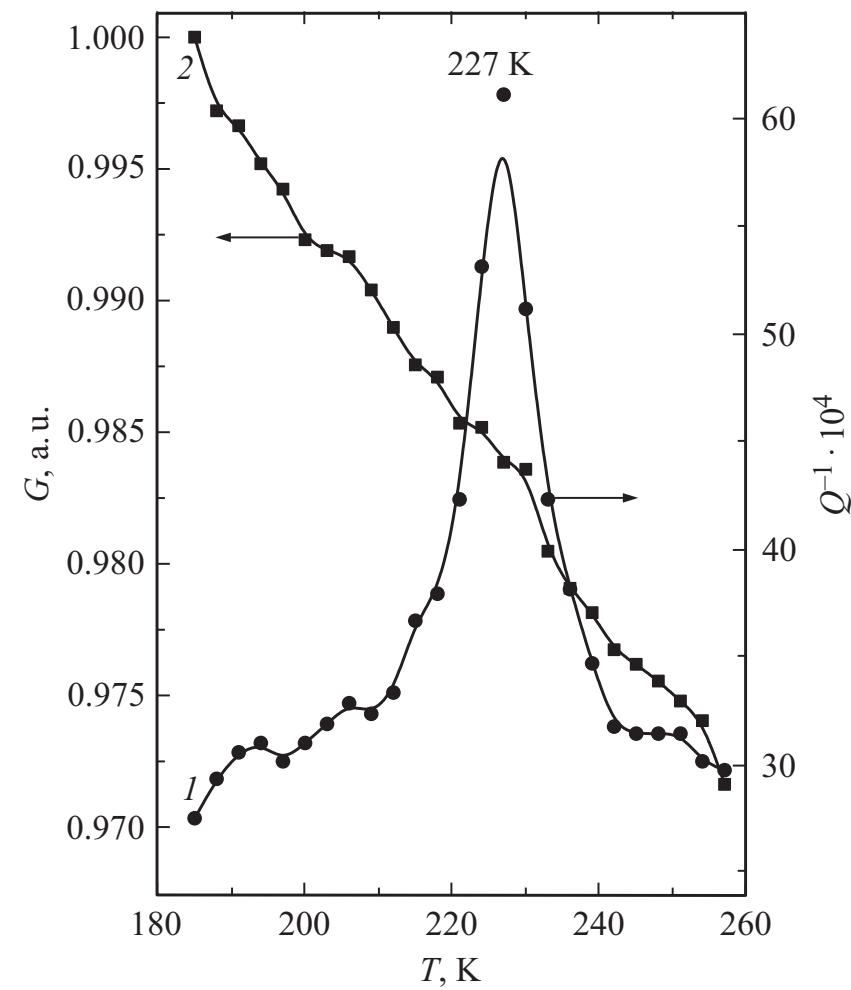

Рис. 3. Температурные зависимости $Q^{-1}$ (кривая 1 ) и $G$ (кривая 2) нанокомпозита $\mathrm{Co}_{80}\left(\mathrm{CaF}_{2}\right)_{20}$.

При этом наиболее существенный рост $Q^{-1}$ отмечен для образцов $\mathrm{Co}_{x}\left(\mathrm{CaF}_{2}\right)_{100-x}$ с высокой концентрацией металлической фазы $(x \geqslant 45$ at.\%). Экспериментально наблюдаемое возрастание внутреннего трения, называемое высокотемпературным фоном, в интервале температур 650-750 K удовлетворительно описывается уравнением [4]:

$$
Q^{-1}=Q_{0}^{-1} \exp \left(-\frac{E_{F}}{k T}\right) .
$$

Здесь $Q_{0}^{-1}$ постоянная, $E_{F}-$ энергия активации высокотемпературного фона.

Экспоненциальный рост $Q^{-1}$ подтверждается линейной зависимостью $\ln Q^{-1}(1 / T)$, показанной на рис. 5, угол наклона которой определяется энергией активации высокотемпературного фона внутреннего трения. Видно (рис. 5), что выше критической температуры $\left(T_{c}=675 \mathrm{~K}\right)$ имеет место увеличение энергии активации $E_{F}$.

Так, в случае образцов $\mathrm{Co}_{x}\left(\mathrm{CaF}_{2}\right)_{100-x}$ до порога перколяции $(x<45$ at.\%) в интервале температур до $T_{c}$ на низкотемпературном участке энергия активации фона составила $E_{F 1}=0.22 \pm 0.05 \mathrm{eV}$, а выше $T_{C}$ на высокотемпературном участке энергия активации фона $E_{F 2}=0.44 \pm 0.05 \mathrm{eV}$ (рис. 5,a). С увеличением концентрации металлической фазы $x>45$ at.\% энергия активации фона $Q^{-1}$ возрастает и составляет $E_{F 1}=0.85 \pm 0.05 \mathrm{eV}$ на низкотемпературном и
$E_{F 2}=1.8 \pm 0.1 \mathrm{eV}$ на высокотемпературном участке для нанокомпозита $\mathrm{Co}_{60}\left(\mathrm{CaF}_{2}\right)_{40}$ (рис. $\left.5, b\right)$. При дальнейшем увеличении концентрации металлической фазы $x$ энергия активации фона $Q^{-1}$ незначительно возрастает и составляет для первого участка $E_{F 1}=0.9 \pm 0.05 \mathrm{eV}$ и для второго участка $E_{F 2}=1.9 \pm 0.1 \mathrm{eV}$ в случае нанокомпозита $\mathrm{Co}_{75}\left(\mathrm{CaF}_{2}\right)_{25}$ (рис. 5, $\mathrm{c}$ ).

Предположим, что экспоненциальный рост $Q^{-1}$ обусловлен термически активированной миграцией вакансий в металлических включениях. Тогда для низкотемпературного участка, когда диффузионная длина $l$ мигрирующих точечных дефектов за период колебаний меньше диаметра гранулы $(l<d)$, зависимость $Q^{-1}(T)$ может быть описана формулой [9]:

$$
Q^{-1} \sim n l \sim n \sqrt{D t} \sim \frac{n}{\omega^{1 / 2}} \exp \left(-\frac{E_{m}}{2 k T}\right),
$$

где $D-$ коэффициент диффузии; $E_{m}-$ энергия активации миграции дефекта; $\omega=2 \pi f-$ круговая частота; $n$ - концентрация дефектов; $t-$ время.

Если $l>d$, то на высокотемпературном участке за период колебаний точечные дефекты будут успевать мигрировать на всю толщину металлической гранулы,
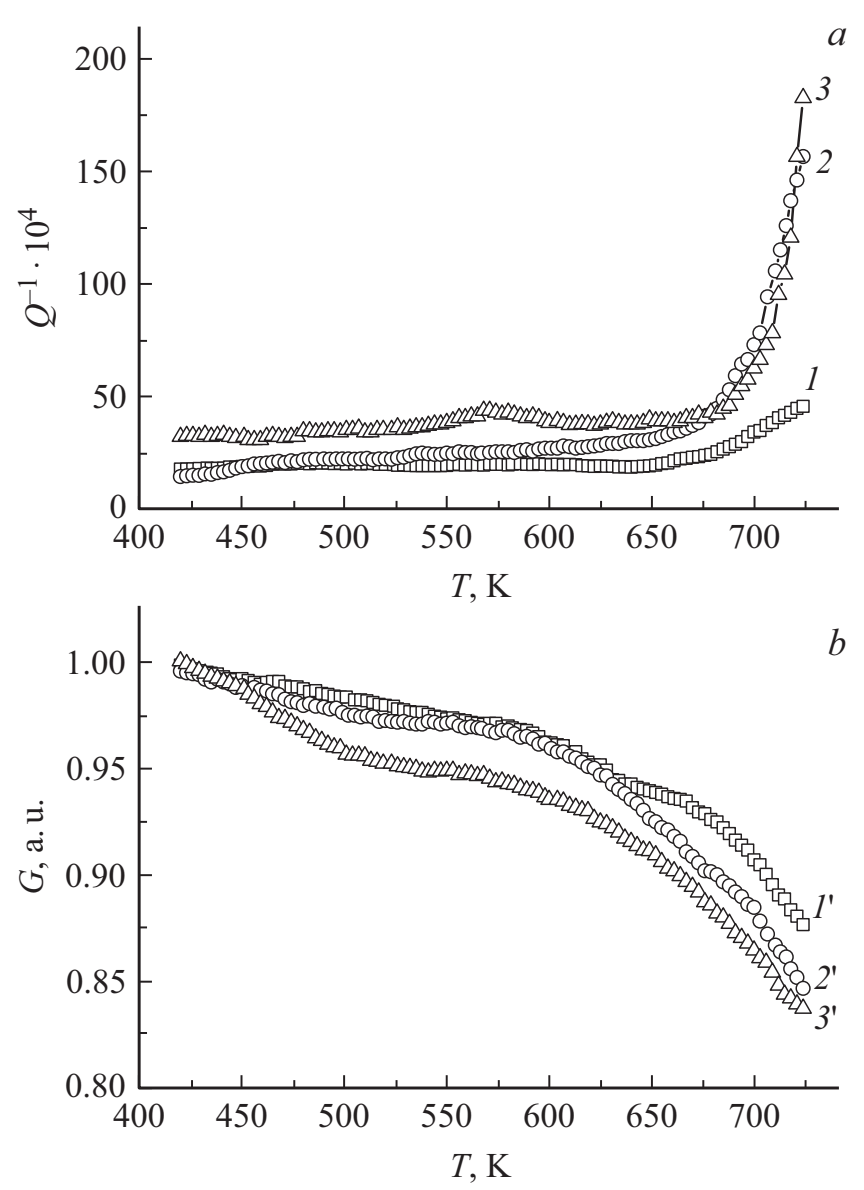

Рис. 4. Температурные зависимости $Q^{-1}(a)$ и $G(b)$ нанокомпозитов $\mathrm{Co}_{x}\left(\mathrm{CaF}_{2}\right)_{100-x}$ при различной концентрации металлической фазы $x$, at.\%: $1,1^{\prime}-41 ; 2,2^{\prime}-65 ; 3,3^{\prime}-$ 73. 

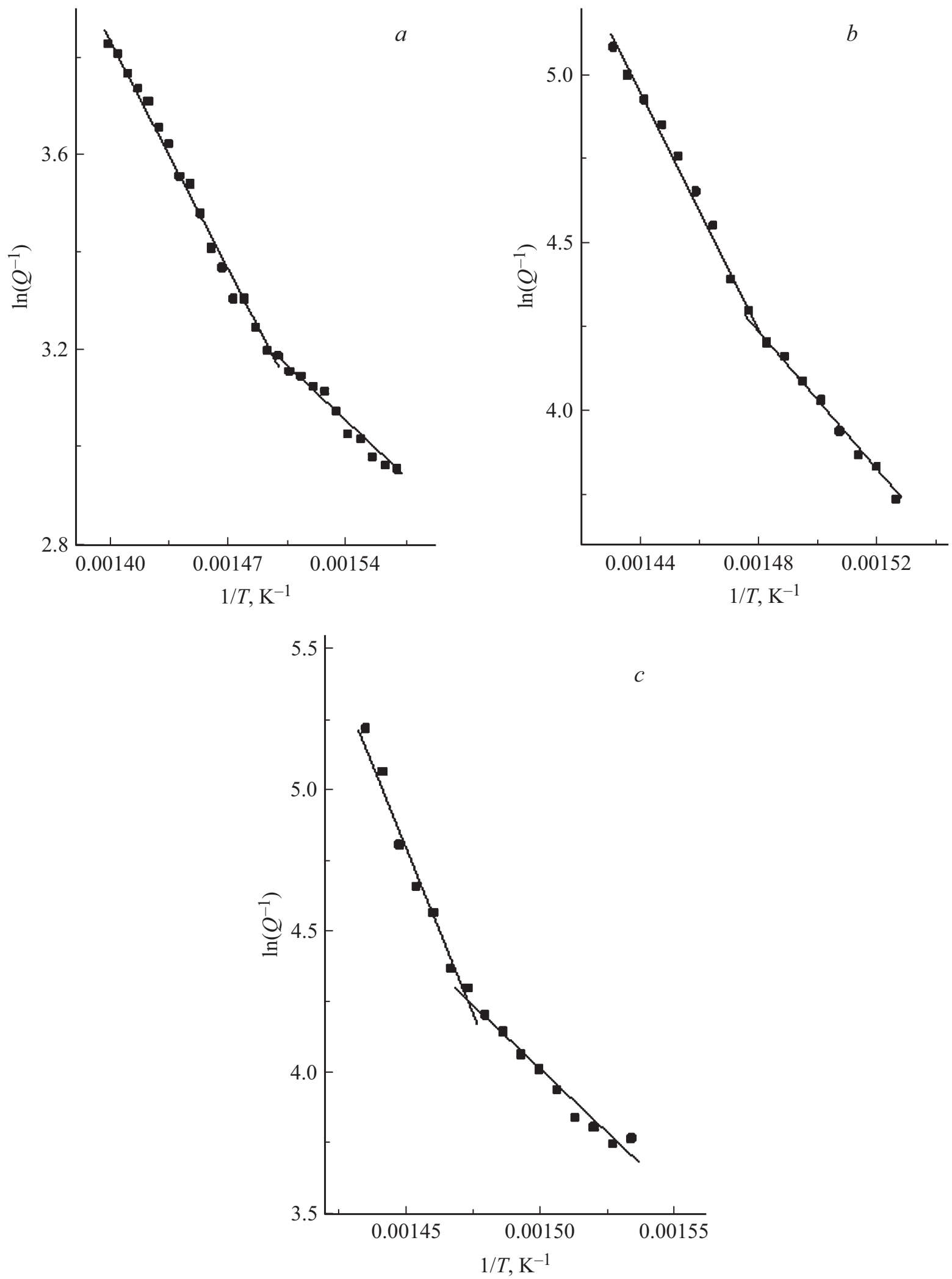

Рис. 5. Зависимости логарифма внутреннего трения от обратной температуры нанокомпозитов: $a-\mathrm{Co}_{41}\left(\mathrm{CaF}_{2}\right)_{59}, b-$ $\mathrm{Co}_{60}\left(\mathrm{CaF}_{2}\right)_{40}, c-\mathrm{Co}_{75}\left(\mathrm{CaF}_{2}\right)_{25}$. 
и зависимость $Q^{-1}(T)$ будет описываться соотношением [6]:

$$
Q^{-1} \sim \frac{n}{\omega} \exp \left(-\frac{m}{k T}\right) .
$$

Таким образом, обнаруженное в эксперименте удвоение энергии активации фона внутреннего трения при температурах выше $675 \mathrm{~K}$ уместно связать с увеличением диффузионной длины $l$ и переходом от условия $l<d$ к условию $l>d$, что естественно ожидать для наногранулированных систем. В этом случае значение энергии активации миграции дефекта совпадает с величиной энергии активации фона внутреннего трения.

Переход от одного участка к другому с разными наклонами не является резким, а происходит в некотором температурном интервале, ширина которого связана с разбросом в размерах образующихся гранул [10].

Эксперимент показал увеличение энергий $E_{F 1}$ и $E_{F 2} \mathrm{c}$ ростом концентрации х. Вероятно, это связано с изменением состояния границ гранул (зерен). В композитах с относительно невысокой концентрацией Со металлические гранулы изолированы. В этом случае имеет смысл говорить о диффузии дефектов вдоль межфазных границ при возбуждении механических напряжений.

Для композиционных материалов с концентрацией $x=75$ at.\% металлические гранулы соприкасаются, и формируется лабиринтная сетка из соединенных друг с другом гранул (рис. 1). Таким образом, в этих материалах наряду с межфазными присутствуют межгранульные (межзеренные) границы. Можно предположить, что энергия активации диффузии вакансиоподобных дефектов по межзеренным границам выше, чем вдоль межфазных границ, что и приводит к наблюдаемому в эксперименте повышению значения энергий $E_{F 1}$ и $E_{F 2}$, с ростом содержания металлической фракции.

\section{Заключение}

Проведенные исследования показали, что полученные материалы в исходном состоянии представляют собой наногранулированные системы с размерами гранул около $3 \mathrm{~nm}$. В области температур $227 \mathrm{~K}$ для исследуемых гранулированных нанокомпозитов $\mathrm{Co}_{x}\left(\mathrm{CaF}_{2}\right)_{100-x}$ был обнаружен пик $Q^{-1}$. При этом установлено, что его высота уменьшается по мере уменьшения содержания металлической фазы в композитах, а в случае составов с малой концентрацией металлической фазы данные пики в условиях эксперимента не выявляются. Это свидетельствует о том, что ответственными за обсуждаемые аномалии $Q^{-1}$ являются процессы, протекающие в металлических включениях.

Выше $650 \mathrm{~K}$ с увеличением температуры имеет место существенный рост зависимости $Q^{-1}(T)$, вызванный диффузионным движением вакансий в гранулах Со в условиях ограниченной геометрии. На основе анализа экспериментальных результатов можно сделать вывод о том, что экспоненциальный рост внутреннего трения, наблюдаемый для нанокомпозитов системы в области температур 650-750 K, преимущественно обусловлен термически активированной миграцией вакансиоподобных дефектов по поверхности металлических гранул.

Обнаруженное в эксперименте удвоение энергии активации фона внутреннего трения при температурах выше $675 \mathrm{~K}$, связано с переходом от режима, при котором диффузионная длина вакансий меньше размеров гранул, к режиму, когда диффузионная длина превышает размеры гранул.

\section{Список литературы}

[1] Stognei O.V., Kalinin Yu.E., Zolotukhin I.V., Sitnikov A.V., Wagner V., Ahltrs F.J. // J. Physics: Cond. Matter. 2003. Vol. 15. P. 4267-4277.

[2] Калинин Ю.Е., Котов Л.Н., Петрунёв С.Н., Ситников А.В. // Известия РАН. сер. физическая. 2005. Т. 69. Вып. 8. С. 1195-1199.

[3] Постников В.С. Внутреннее трение в металлах. М.: Металлургия, 1974. $352 \mathrm{c}$.

[4] Даринский Б.М., Калинин Ю.Е., Самцова Н.П. // Известия РАН. сер. физическая. 1998. Т. 62. № 7. С. 1359-1364.

[5] Тарасов Д.П. // ЖТФ. 2017. Т. 87. Вып. 9. С. 1384-1388.

[6] Тарасов Д.П., Калинин Ю.Е., Ситников А.В. // Письма в ЖТФ. 2008. Т. 34. Вып. 11. С. 12-18.

[7] Tarasov D.P., Korotkov L.N., Sitnikov A.V. // Ferroelectrics. 2010. Vol. 397. N 1. P. 185-190.

[8] Тарасов Д.П., Калинин Ю.Е., Коротков Л.Н., Ситников А.В. // Письма в ЖТФ. 2009. Т. 35. Вып. 1. С. 90-97.

[9] Золотухин И.В., Калинин Ю.Е. // ФТТ. 1995. Т. 37. Вып. 2. C. $536-545$.

[10] Тарасов Д.П., Коротков Л.Н., Дешевых В.В., Кульков В.Г. // Композиты и наноструктуры. 2012. № 2. С. 24 34. 